\title{
An Assessment of the Efficacy of Ofloxacin Brands on Clinical Isolates of Streptococcus Pneumoniae and Staphylococcus Aureus
}

\author{
Eguono Esther Anomohanran ${ }^{1} \&$ Ubreye Benjamin Owhe-Ureghe ${ }^{1}$ \\ ${ }^{1}$ Department of Microbiology, Delta State University, Abraka, Delta State, Nigeria \\ Correspondence: Eguono Esther Anomohanran, Department of Microbiology, Delta State University, Abraka, \\ Delta State, Nigeria. Tel: 80-6572-5780. E-mail: a_eguono@yahoo.com
}

Received: February 8, 2015

Accepted: March 13, 2015

Online Published: May 22, 2015

doi:10.5539/mas.v9n9p35

URL: http://dx.doi.org/10.5539/mas.v9n9p35

\begin{abstract}
It is a common practice for clinicians to administer antimicrobial agents to patients suffering from bacterial infections without recourse to laboratory diagnosis which provides information on the antibiogram of the etiologic agents. This may result to the use of less efficacious drugs that might lead to long time hospitalization, death of patients and/or opportunity for bacterial species to develop resistant to some of these antimicrobial agents. This is the reason why, this study was carried out to determine the efficacy of five (5) brands of Ofloxacin; a typical floroquinolone antibiotic available in most pharmaceutical shops in Nigeria. Clinical isolates of Streptococcus pneumoniae and Staphylococcus aureus were exposed to twofold serial dilution of the antibiotic to determine the minimum inhibitory concentration (MIC). Result shows that the percentage strains of Streptococcus pneumoniae inhibited by the five brands of Ofloxacin investigated were 72, 74, 41, 68 and 76\% respectively. Result also shows that the percentage strains of Staphylococcus aureus inhibited by the antimicrobial agent were $81,85,52,79$ and $85 \%$ respectively. Analysis of the result shows that the efficacy rate of Ofloxacin against Streptococcus pneumoniae and Staphylococcus aureus were 72 and $81 \%$ respectively. The result has shown that patients and health care providers can rely on this antimicrobial agent in the treatment of ailments associated with Streptococcus pneumoniae and Staphylococcus aureus in this locality provided the efficacy of the brand to be used is tested.
\end{abstract}

Keywords: Ofloxacin, Staphylococcus aureus, Streptococcus pneumoniae, antimicrobial agent, drug resistance, antibiogram, drug efficacy, clinical isolates

\section{Introduction}

The effect of using less efficacious antimicrobial agents on patients suffering from bacterial infections or other diseases is associated with increased costs, length of hospitalization and increase in mortality rates (Gales et al., 2012). This is also true of infections caused by isolates which are resistant to some antimicrobial agents. Resistance among Gram-positive organisms in particular is of great concern, since studies have shown that only a few antimicrobial agents are effective to treat infections caused by these pathogens (Robert et al., 2013). The increase of antimicrbial resistance among Gram-positive cocci infections especially with the discovered increase in Staphylococcus aureus to methicillin and the resistance of Streptococcus pneumoniae to penicillin has continues to be a big threat to public health (Zhao et al., 2012). To mitigate this challenge, a lot of studies have been initiated by various groups to track the antimicrobial resistance trends of most Gram-positive cocci.

The level of efficacies of various antimicrobial agents is a crucial health issue that can critically influence the economic and social life of the people. The resistance posed by clinical isolates are based on many factors which are classified as either natural or acquired. Natural resistance refers to the inherent capacity available in all strains of a species to survive and grow in the presence of an anti-infectious agent, while acquired resistance is the one observed in some strains of a species wherein all members were in the past susceptible to that agent (Rene et al., 2012). The desire to enable an antimicrobial agent to be effective over a long period requires that the use of the drug be monitored in all situations.

Staphylococcus aureus is a Gram positive, cocci eubacterium that is found in the mucous membranes and the surface of the human skin. It is an opportunistic pathogen in both animals and humans. It is also one of the most common causes of hospitals and community acquired infections. Most strains of the organism become infectious usually when the skin or mucous membranes are punctured by a variety of objects such as needles and surgical 
devices, and also from common materials such as cloth during washing.

Staphylocossus aureus produces three broad disease types which are superficial infections, systemic infections and toxinoses. Examples of the superficial infections include boils, pimples, and toxic epidermal necrolysis. The infections caused by systemic disease type are pneumoniae, endocarditis and osteomyelitis while for toxicoses, we have food poisoning or toxic shock syndrome. The accumulation of resistance factors has rendered the bacteria immune to a variety of commonly used antimicrobial agents thus increasing the capacity of the bacteria to endure very difficult environments. Staphylococcus aureus over the years has remarkably become a successful pathogen which continues to be a major cause of morbidity and mortality worldwide. This microorganism is the most common causes of nosocomial infections such as intravenous catheter associated infections, ventilator associated pneumoniae and surgical wound infections and are more easily spread from person to person (Uhlemann et al., 2014).

Streptococcus pneumoniae are common causes of respiratory tract infections (Akingbade et al., 2012) and also associated with some antimicrobial resistance (Darabi et al., 2010). Streptococcus pneumoniae is a major cause of morbidity and mortality and the prognosis for patients can vary from quick recovery with minimal functional impairment to severe morbidity with complications leading to death (Jones et al., 2010). Management of infections caused by Streptococcus pneumoniae has placed significant burden on medical and economic resources. For instance, the healthcare costs associated with the treatment of $S$. pneumoniae with Ofloxacin in the USA are estimated to exceed $\$ 10$ billion each year. This is why a further use of antimicrobial agents which are known to be resisted by the pathogens will further contribute to increase in morbidity, mortality and related expenses (Daneman et al., 2008).

The challenge associated with the failure of many antimicrobial agents makes it important for constant evaluation of available brands of antimicrobial agents in the market. Ofloxacin is a broad spectrum antibiotic that is active against both Gram positive and Gram negative bacteria. It functions by inhibiting deoxyribonucleic acid (DNA) gyrase, a type II topoisomerase and topoisomerase IV. Topoisomerase IV is an enzyme necessary to separate replicated DNA, hence it is capable of preventing cell division (Drlica and Zhao, 1997; Willey et al., 2011). Ofloxacin is available as tablets, oral solution and injectable solution. It is also used as ear and eye drops. Ofloxacin has been used for the treatment of established severe and life threatening bacterial infections such as acute bacterial exacerbations of chronic bronchitis, community acquired pneumonia, skin structure infections, nongonococcal urethritis and cervicitis, mixed infections of the urethra and cervic, acute pelvic inflammatory disease, uncomplicated cystitis, complicated urinary tract infections, prostatitis and acute urethral and cervical gonorrhea.

Due, to growing prevalence of antibiotic resistance, and the fact that Ofloxacin, (a floroquinolone) has become popular among clinicians in the treatment of bacterial infections, this study was carried out to evaluate the susceptibility level of clinical isolates of Streptococcus pneumoniae and Staphylococcus aureus against Ofloxacin. This study will therefore add to the limited data on crucial public health issue in this country.

\section{Materials and Methods}

\subsection{Collection of Isolates}

Ten clinical samples each were collected from patients suffering from upper respiratory and wound infections attending the outpatient department (OPD) of five (5) Government hospitals in Delta State, Nigeria. The hospitals include, Delta State University Teaching Hospital Oghara, Central Hospital Warri, Baptist Hospital Eku, Delta State University Health Centre Abraka and Specialist Hospital Asaba. The samples were cultured on freshly prepared blood and chocolate ager plates using standard microbiological techniques. The isolates obtained were sub cultured to obtain pure cultures which were biotyped according to the techniques prescribed by Cowan and Steel (2004). The isolates were identified as Streptococcus pneumonieae and Staphylococcus aureus. These organisms were kept on agar slant for use as test isolates.

\subsection{Antimicrobial Susceptibility Test}

The antimicrobial susceptibility test was carried out using the broth dilution methodology after the procedure of Darabi et al. (2010). The minimal inhibitory concentrations (MIC), which is the lowest concentration of drug that is capable of preventing visible growth of microorganisms were determined by a twofold serial dilution technique in brain heart infusion broth. Approximately $2 \times 10^{4}$ to $4 \times 10^{4} \mathrm{CFU} / \mathrm{mL}$ were incubated and tubes were examined for turbidity after incubation for 24 hours in air. The MIC was determined in accordance with the recommendation of National Committee for Clinical Laboratory Standards, NCCLS (Cheesbrough, 2002). Ofloxacin consisting of $400 \mathrm{mg}$ was dissolved into $100 \mathrm{ml}$ sterile distilled water. Then $1 \mathrm{~mL}$ of sterile prepared 
nutrient broth was measured into a sterile test tube and serially diluted tenfold together with already prepared stock solution of $1 \mathrm{~mL}$ of the antibiotic arranged in the test tube rack. An aliquot $(0.5 \mathrm{~mL})$ of the test organism previously adjusted to the McFarland standard was then introduced into the test tubes. The same method was used for the control but in this case the antibiotic was not introduced into the tubes. The set up was incubated at $37{ }^{\circ} \mathrm{C}$ for 24 hours (Andrews, 2001; Chayani, et al., 2009 and Wiegand et al., 2008). Organisms inhibited by Ofloxacin at a concentration of $2 \mu \mathrm{g} / \mathrm{mL}$ or less per $\mathrm{mL}$ were considered susceptible, while those inhibited by concentrations greater than $2 \mu \mathrm{g} / \mathrm{mL}$ were designated resistant. This concentration was chosen because according to Capoor, et al. (2009), it represents a level that may possibly be achievable in human serum without significant risk of toxicity.

\section{Results and Discussion}

The 240 clinical isolates recovered from the clinical samples were subjected to susceptibility test to five different brands of Ofloxacin. It is established that Ofloxacin exhibits in vitro minimum inhibitory concentration of 2 $\mu \mathrm{g} / \mathrm{mL}$ or less against most strains of bacteria such as Streptococcus pnermoniae, Staphylococcus epidemidis, Staphylococcus saprophyticins and Staphylococcus aureus (Murray et al., 1999; Capoor et al., 2009). This MIC standard of $2 \mu \mathrm{g} / \mathrm{mL}$ is thus applied in analysing results obtained in this study.

The susceptibility result showing the relationship between the percentage strains inhibited by various concentration of Ofloxacin and the clinical isolates of Streptococcus pneumoniae and Staphylococcus aureus for brand $\mathrm{A}$ is presented as shown in Figure 1. This figure shows that the percentage of strains inhibited by Ofloxacin at a concentration of $2 \mu \mathrm{g} / \mathrm{mL}$ for Streptococcus pneumoniae and Staphylococcus aureus were 72 and $81 \%$ respectively. The percentage of strains inhibited by Ofloxacin at $2 \mu \mathrm{g} / \mathrm{mL}$ for brands B, C, D and E as shown in Figures 2, 3, 4 and 5 were 74 and 85\%; 41 and 52\%; 68 and 79\%; 76 and 85\% for Streptococcus pneumoniae and Staphylococcus aureus respectively.

Analysis of this result shows that the strains of Streptococcus pneumoniae inhibited by Ofloxacin for the various brands are 72, 74, 41, 68 and 76\% respectively. This gives an average efficacy of $66.2 \%$. The percentage strains of Staphylococcus aureus inhibited by the antimicrobial agent are 81, 85, 52, 79 and 85\% respectively. This gives an average efficacy of $76.4 \%$ for Staphylococcus aureus.

A further analysis of the result shows that brand $\mathrm{C}$ had a very low inhibitory rate among all the brands with an efficacy value of 41 and 52\% for Streptococcus pneumoniae and Staphylococcus aureus respectively. This low value associated with brand $\mathrm{C}$ could be related to either environmental factors or an attempt by the manufacturer to fake the drug. Since resistance of clinical isolates to floroquinolone antibiotics is very low compared to other antibiotics, this low efficacy associated with just one among the five brands could not be associated with resistance of the clinical isolates to the antimicrobial agent.

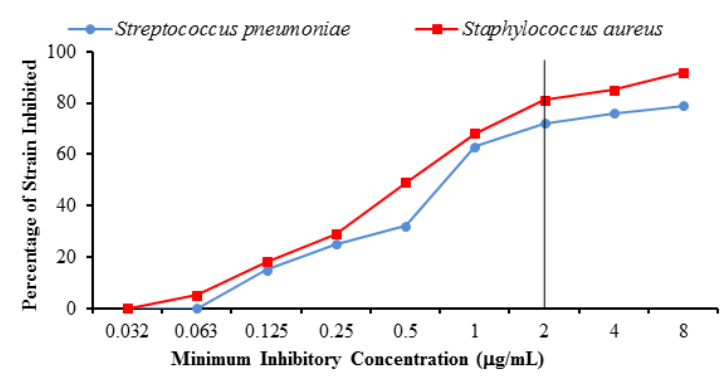

Figure 1. Percentage of strains inhibited at various inhibitory concentrations of Ofloxacin for brand A

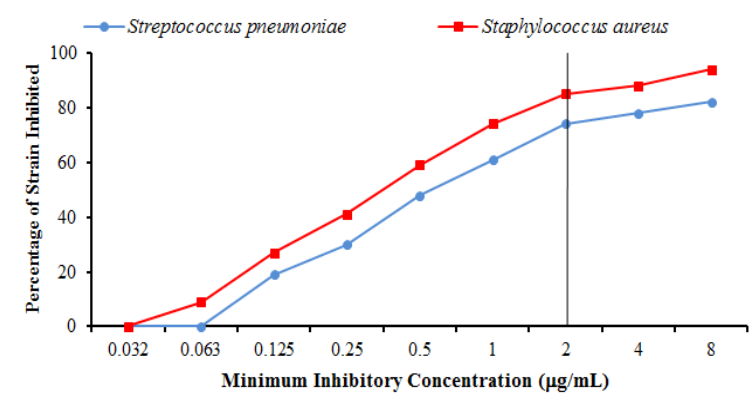

Figure 2. Percentage of strains inhibited at various inhibitory concentrations of Ofloxacin for brand B 


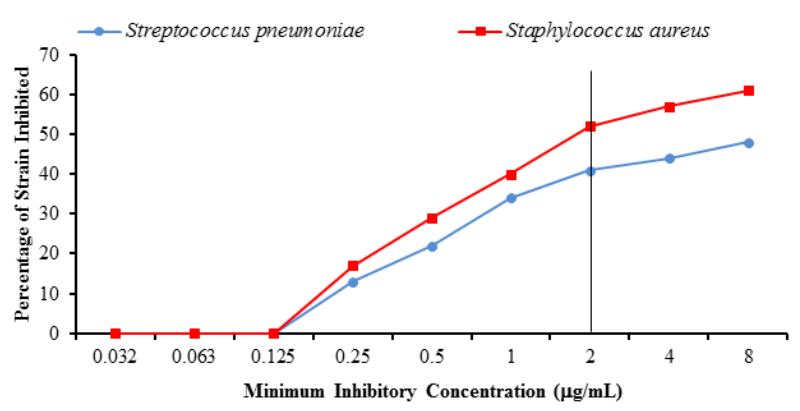

Figure 3. Percentage of strains inhibited at various inhibitory concentrations of Ofloxacin for brand C

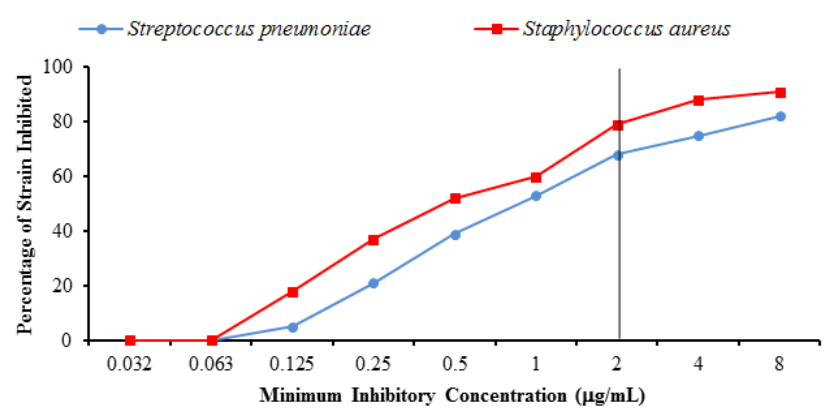

Figure 4. Percentage of strains inhibited at various inhibitory concentrations of Ofloxacin for brand D

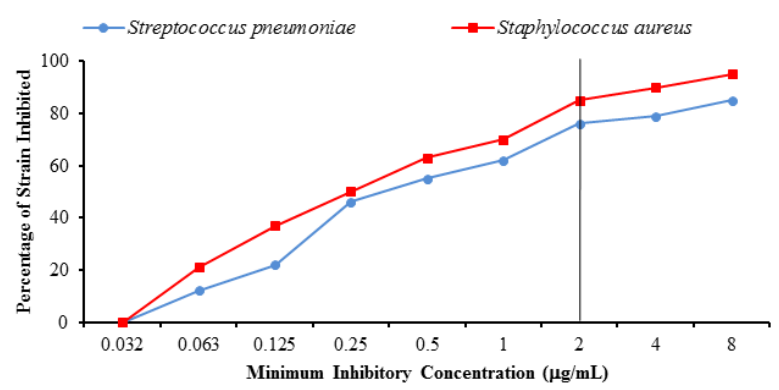

Figure 5. Percentage of strains inhibited at various inhibitory concentrations of Ofloxacin for brand $\mathrm{E}$

However, for the poor result of brand C, the efficacy level of Streptococcus pneumoniae is $73 \%$ while that of Staphylococcus aureus is $83 \%$. This result agrees with the findings of Zhao et al., (2012) that $27.4 \%$ of the isolates collected from skin and soft tissue infections where resistant to Ofloxacin meaning that the antimicrobial agent was $72.6 \%$ effective against Staphylococcus aureus. Zhao et al. (2012) also asserted that Streptococcus pneumoniae had $96.5 \%$ susceptibility rate as at the period of 2005 to 2010 . This value is about $20 \%$ higher than what is obtained in this study.

This difference is not unconnected with the low value of brand $\mathrm{C}$ which show very low efficacy. The percentage values of the antimicrobial susceptibility obtained in this study have shown clearly that patients and health care providers can as a matter of facts rely or depend on this antimicrobial agent in the treatment of ailments associated with Streptococcus pneumoniae and Staphylococcus aureus provided it is of good quality. The reason which could be adduced for the high efficacy of Ofloxacin unlike other antibiotics which shows lower efficacy according to the findings of Anomohanran et al. (2014) is that Ofloxacin is less frequently used when compared to most antibiotics available in pharmaceutical shops.

The result of this study has also shown that the application of the antimicrobial agent on Staphylococcus aureus is a little more effective than when applied to Streptococcus pneumoniae by a factor of $10 \%$. For more serious infections, a high dose which may not be toxic to the body can be applied to increase the efficacy of the antimicrobial agent used in this study. 


\section{Conclusion}

Result from this study has shown that the percentage strain of Streptococcus pneumonia inhibited by Ofloxacin for the five brands investigated are 72, 74, 41, 68 and 76\% respectively. Result also shows that the percentage strains inhibited by the antimicrobial agent to Staphylococcus aureus are 81, 85, 52, 79 and 85\% respectively. Analysis of the result shows that the efficacy rate of Ofloxacin on Streptococcus pneumoniae and Staphylococcus aureus are 72 and $81 \%$ respectively. Results further indicate that one out of the five brands of the antibiotic shows an efficacy that is less than average. This low efficacy observed with brand $\mathrm{C}$ could be linked to environmental factors (that is storage condition) or attempt by the manufacturer to fake the drug. The study has therefore shown that the clinical isolates investigated can be inhibited if the drug in the patient reaches the concentration required to treat the ailment. This study therefore suggest that this floroquinolone (Ofloxacin) is a drug of choice in the treatment of infections caused by Streptococcus pneumoniae and Staphylococcus aureus provided the drug is taken as recommended by the manufacturer.

\section{References}

Andrews, J. M. (2001). Determination of Minimum Inhibitory Concentration. Journal of Antimicrobial Chemotherapy, 48, 515-516.

Anomohanran, E. E., Owhe-Ureghe, U. B., \& Ehwarieme, D. A. (2014). Evaluating the Sensitivity of Pseudomonas aeruginosa, Escherichia coli and Salmonella typhi to various brands of Ampicillin and Amoxicillin available in Nigeria. American Journal of Agricultural and Biological Sciences, 9(4), 503-509. http://dx.doi.org/10.3844/ajabssp.2014.503.509

Akingbade, O. A., Ogiogwa, J. I., Okerentugba, P. O., Innocent-Adiele, H. C., Onoh, C. C. Nwanze, J. C., \& Okonko, I. O. (2012). Prevalence and Antibiotic Susceptibility Pattern of Bacterial Agents Involved in Lower Respiratory Tract Infections in Abeokuta, Ogun State, Nigera. Report and Opinion, 4(5), 25-30.

Capoor, M. R., Nair, D., Posti, J., Singhal, S., Deb, M., Aggarwal, P., \& Pillai, P. (2009). Minimum Inhibitory Concentration of Carbapenems and Tigecycline against Salmonella spp. Journal of Medical Microbiology, 58, 337-341. http://dx.doi.org/10.1099/jmm.0.47853-0

Chayani, N., Tiwari, S., Sarangi, G., \& Mallick, B. (2009). Role of azithromycin against clinical isolates of family Enterobactereriaceae: A comparison of its minimum inhibitory concentration by three different methods. Indian Journal of Medical Microbiology, 27(2), 107-110.

Cheesbrough, M. (2002). Medical laboratories manual for tropical countries, II Microbiology (ELBS). Butterworth Kent, London. pp. 23-78.

Cowan, I. and Steel, K. J. (2004). Manual for the Identification of Medical Bacteria ( ${ }^{\text {rd }}$ Edn.), Cambridge University Press, United Kingdom, pp. 15-20.

Daneman, N., Low, D. E., McGeer, A., Green, K. A., \& Fisman, D. N. (2008). At the threshold: defining clinically meaningful resistance thresholds for antibiotic choice in community-acquired pneumonia. Clinical Infectious Diseases, 46, 1131-1138.

Darabi, A., Hocquet, D., \& Dowzicky, M. J. (2010). Antimicrobial activity against Streptococcus pneumoniae and Haemophilus influenzae colleced globally between 2004 and 2008 as part of the Tigecycline Evaluation and Surveillance Trial. Diagnostic Microbiology and Infectious Disease, 67, 78-86. http://dx.doi.org/10.1016/j.diagmicrobio.2009.12.009

Drlica, K., \& Zhao, X (1997). DNA gyrase, topoisomerase IV and the 4-quinolones. Microbiology Molecular Biology Reviews, 61(3), 377-392.

Gales, A. C., Castanheira, M. Jones, R. N., \& Sader, H. S. (2012). Antimicrobial resistance among Gram-Negative Bacilli isolated from Latin America: Results from Sentry Antimicrobial survellance program (2008-2010), Diagnostic Microbiology and Infectious Disease, 73, 354-360. http://dx.doi.org/10.1016/j.diagmicrobio.2012.04.007

Jones, R. N., Jacobs, M. R., \& Sader, H. S. (2010). Evolving trends in Streptococcus pneumoniae resistance: implications for therapy of community-acquired bacterial pneumonia, International Journal of Antimicrobial Agents, 36, 197-204. http://dx.doi.org/10.1016/j.ijantimicag.2010.04.013

Murray, P. R., Baron, E. J. O., Pfaller, M. A., Tenover, F. C., \& Yolken, R. H. (1999). Manual of Clinical Microbiology ( $7^{\text {th }}$ Edn.). ASM Press, Washington, DC. pp. 1532-1533.

Rene, F. K. P., Jonas, K., Patrice, M. Diane, Y., Adamou, N., Pierre, W. J., Josue, S. L., Kaba, K., \& Lazare, K. 
(2012). Antibiotic Resistance in Escherichia coli Isolated from Women Genitalia and Trend of Minimal Inhibiting Concentration in a Semi-Urban Population: Bangangte, West-Cameroon. Current Research Journal of Biological Sciences, 4(6), 696-701.

Robert, M, Eid, E. P., Saint-Antoine, P., \& Harissi-Dagher, M. (2013). Microbial Colonization and Antibacterial Resistance Patterns after Boston Type 1 Keratoprosthesis. Ophthalmology, 120, 1521-1528. http://dx.doi.org/10.1016/j.ophtha.2013.01.003.

Uhlemann, A., Otto, M., Lowy, F. D., \& Deleo, F. R. (2014). Evolution of Community and healthcare Associated Methicillin Resistant Staphylococcus aureus. Infection, Genetics and Evolution, 21, 563-574. http://dx.doi.org/10.1016/j.meegid.2013.04.030

Wiegand, I., Hilpert, K., \& Hancock, R. (2008). Agar and broth dilution methods to determine the minimal inhibitory concentration of antimicrobial substances. Nature Protocols, 3(2), 163-175.

Willey, M. J., Sherwood, M. L., \& Woolverton, J. C. (2011). Antimicrobial Chemotherapy in: Prescott's Microbiology ( $8^{\text {th }}$ Edn.) McGraw-Hill International Edition, New York. pp. 826-849.

Zhao, C., Sun, H., Wang, H., Liu, Y., Hu, B., \& Yu, Y. et al. (2012). Antimicrobial resistance trend among 5608 clinical Gram-positive isolates in China: Results from the Gram-Positive Cocci Resistance Surveillance Program (2005-2010). Diagnostic Microbiology and Infectious Disease, 73, 174-181. http://dx.doi.org/10.1016/j.diagmicrobio.2012.03.003

\section{Copyrights}

Copyright for this article is retained by the author(s), with first publication rights granted to the journal.

This is an open-access article distributed under the terms and conditions of the Creative Commons Attribution license (http://creativecommons.org/licenses/by/3.0/). 